\title{
MODELLING THE IMPACT OF BIOLOGICAL CONTROL AGENTS
}

\author{
N.D. BARLOW and S.L. GOLDSON*
}

Ministry of Agriculture and Fisheries, Biological Modelling Unit, Private Bag, Levin *P.O. Box 24, Lincoln

A public perception of risk and a growing aversion to things alien in the environment (Waage and Greathead 1989) are likely to place increasing demands on the selection and evaluation of classical biological control agents. It will be increasingly important to select agents that will pose little risk to the environment and do an effective job of control.

In spite of its hitherto limited contribution (Waage 1989), modelling offers a number of potential benefits to aid in this process. These are:

1. Predicting the outcome and probable success of a specific introduction.

2. Aiding in the selection of the most appropriate agent(s).

3. Predicting the impact of exotic agents on ecosystems and non-target species.

4. Increasing understanding of the processes involved.

5. Aiding in the identification and interpretation of critical field data.

6. Identifying optimum integrated management strategies for biocontrol agents.

A New Zealand example: the impact of Microctonus aethiopoides on Sitona discoideus

Based on extensive population data on Sitona before and after introduction of the parasite (Goldson et al 1988) and on the parasite itself (Goldson et al 1989), a model has been developed which accounts for the impact of observed percent parasitism and predicts the future course of the parasite/host interaction (Fig. 1). Spring drought is the main disturbing factor, through its adverse effect on larval establishment, and the patterns in Fig. 1 are based on random incidences of spring droughts after 1988 with an annual probability of 0.25 .

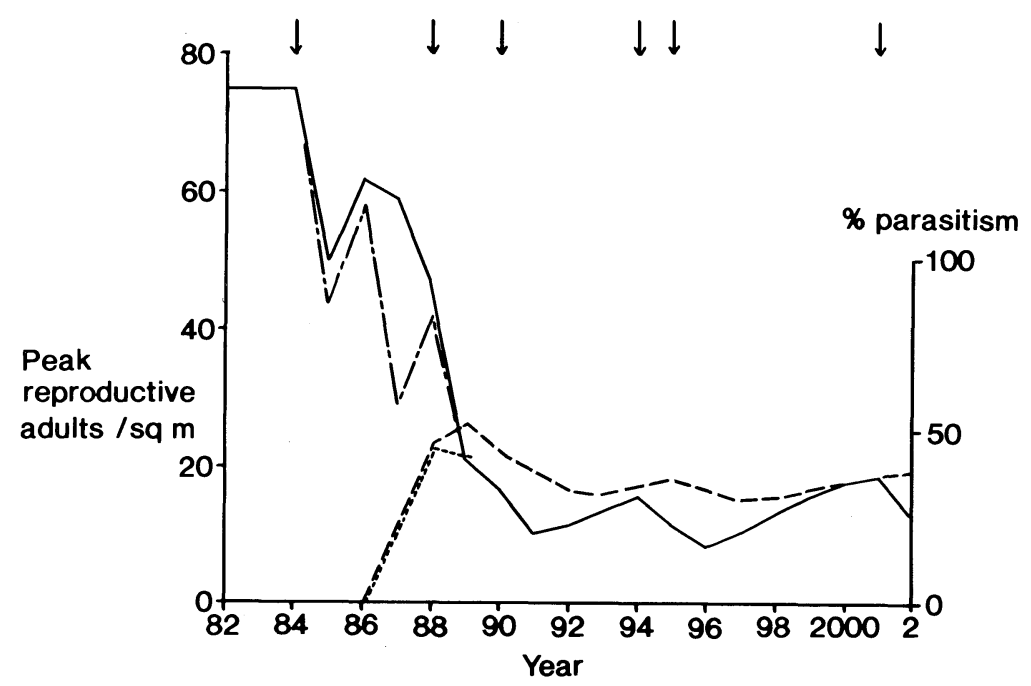

Fig. 1: Sitona adult densities ( $-\longrightarrow-$ observed, $-\longrightarrow$ model) and levels of parasitism (------ observed, - _ _ - model), for a stand at Darfield. Arrows indicate years with spring droughts.

Proc. 43rd N.Z. Weed and Pest Control Conf. 1990: 282-283 
The eventual outcome predicted by the model is a $75 \%$ reduction in reproductive adult density, and $38 \%$ parasitism of those that remain. The net effect is an $85 \%$ overall reduction in recruitment, since parasitised adults do not reproduce. Given the strong density-dependence in larval establishment (Goldson et al 1988), this translates to a $60 \%$ reduction in peak larval densities, from 3600 to $1400 / \mathrm{m}^{2}$ in 1 year old lucerne stands and from 1200 to $500 / \mathrm{m}^{2}$ in 5 year old stands. Since this brings larval densities close to or below the damage thresholds for all stand ages (Goldson and Proffitt 1989), there is every likelihood that no additional management will be required where the parasite is established.

The model has therefore predicted a final outcome of the parasite's introduction, increased our understanding of the processes involved, helped to identify the field data required, and suggested likely management needs.

One of the major contributions of models such as this will be in helping to develop a 'library' of well-analysed case studies, both successful and unsuccessful, which is an essential prerequisite for future improvements in biological control practice. Here retrospective modelling is as useful as genuinely predictive studies, which are still extremely uncommon. A classic example of the latter is the early failure to predict the impact of Cyzenis albicans on the winter moth in Canada (Varley and Gradwell 1968), which has often been cited as a reason for rejecting the modelling approach to biological control predictions. However, such failures indicate more a need for greater knowledge than an abandonment of hope, and in this particular case retrospective modelling has explained what was originally inexplicable (May and Hassell 1988). Much has been learned since 1968.

\section{REFERENCES}

Goldson, S.L. and Proffitt, J.R., 1989. The effect of lucerne age on its sensitivity to damage by Sitona discoideus Gyllenhall (Coleoptera: Curculionidae) in Canterbury. Proc. 5th Aus. Conf. on Grassland Invert. Ecol. P.P. Stahle (Ed): 323-331.

Goldson, S.L., Frampton, E.R. and Proffitt, J.R., 1988. Population dynamics and larval establishment of Sitona discoideus (Coleoptera: Curculionidae) in New Zealand lucerne. J. appl. Ecol. 25: 177-195.

Goldson, S.L., Proffitt, J.R. and McNeill, M.R., 1990. New Zealand seasonal biology and ecology of Microctonus aethiopoides (Hymenoptera: Braconidae), a parasitoid of Sitona spp. (Coleoptera: Curculionidae), with special emphasis on its atypical behaviour. J. appl. Ecol. in press.

May, R.M. and Hassell, M.P., 1988. Population dynamics and biological control. Phil. Trans. R. Soc. Lond. B., 318: 129-169.

Varley, G.C. and Gradwell, G.R., 1968. Population models for the winter moth. In: Insect Abundance., Symp. R. ent. Soc. Lond. 4: 132-142.

Waage, J.K., 1989. Ecological theory and the selection of biological control agents. In: Critical Issues in Biological Control, Mackauer, M., and Ehler, L.E. (Eds), Intercept Ltd., Andover, UK: 135-157.

Waage, J.K. and Greathead, D.J., 1988. Biological control: challenges and opportunities. Phil. Trans. R. Soc. Lond. B, 318: 1-18. 